\title{
Estudos sobre a oxidação aeróbia do metano na cobertura de três aterros sanitários no Brasil
}

\author{
Studies on the aerobic methane oxidation at three sanitary \\ landfills covers in Brazil
}

\author{
Cláudia Echevenguá Teixeira \\ Bióloga. Professora Doutora do Departamento de Engenharia Química e pesquisadora do Instituto de Saneamento Ambiental \\ da Universidade de Caxias do Sul (UCS)
}

Jaqueline Corrêa Torves

Bióloga. Mestre em Biotecnologia pela UCS. Técnica do Laboratório de Saneamento da UCS

Alexandra Rodrigues Finotti
Engenheira Civil. Professora Doutora do Departamento de Engenharia Química e diretora do Instituto de Saneamento Ambiental da UCS

Franciele Fedrizzi

Acadêmica de graduação em Engenharia Ambiental da UCS. Bolsista de iniciação científica da UCS

Fernando Antônio Medeiros Marinho

Engenheiro Civil. Professor livre-docente da Escola Politécnica Universidade de São Paulo (EPUSP)

Paula Fernanda Teixeira

Engenheira Civil. Doutora pela EPUSP

\section{Resumo}

A oxidação biológica e aeróbia do metano em materiais de cobertura de aterros de resíduos sólidos urbanos é uma das alternativas para se minimizarem as emissões dos gases de efeito estufa. Este artigo tem como objetivo avaliar a oxidação biológica do metano em material de cobertura de três aterros brasileiros (dois municipais e uma célula experimental). O trabalho consistiu na coleta de amostras dos solos, as quais foram caracterizadas através de ensaios geotécnicos e microbiológicos. Em laboratório, avaliou-se o consumo de metano de uma amostra de cada aterro. Os resultados revelaram a presença de bactérias metanotróficas e consumo de metano em laboratório, o que sugere que exista uma relação inversa entre o grau de saturação no momento da coleta e o número de bactérias metanotróficas.

Palavras-chave: aterro sanitário; metano; aquecimento global; efeito estufa; bactérias metanotróficas; oxidação aeróbica do metano; resíduos sólidos; cobertura.

\begin{abstract}
The biological and aerobic oxidation of methane within the soil cover of municipal solid waste landfills is one an alternative to minimize emissions of greenhouse effect gases. This study aims at assess the biological oxidation of methane within the final cover of three landfills in Brazil (two municipal ones and one experimental cell). The soil samples obtained from the landfill cover were characterized by geotechnical and microbiological tests. In the laboratory the consumption of methane from each sample were evaluated. The results revealed the presence of methanotrophic bacteria and consumption of methane in the laboratory was observed, which also suggest that there is an inverse relation between the degree of saturation at the time of sampling and the number of methanotrophic bacteria.
\end{abstract}

Keywords: sanitary landfill; methane; global warming; greenhouse effect; methanotrophic bacteria; methane oxidation; solid waste; landfill cover. 


\section{Introdução}

O metano $\left(\mathrm{CH}_{4}\right)$ é um dos gases responsáveis pelo efeito estufa e possui uma ação 25 vezes maior do que o dióxido de carbono $\left(\mathrm{CO}_{2}\right)$ em relação à retenção do calor responsável pelo aquecimento estimado do planeta ao longo de cem anos (INTERGOVERNMENTAL PANEL ON CLIMATE CHANGE, 2007). A degradação anaeróbia de resíduos sólidos nos aterros sanitários é uma fonte importante de produção antropogênica desse gás. Os aterros são responsáveis por 10 a $20 \%$ das emissões de metano geradas pela atividade antropogênica (INTERGOVERNMENTAL PANEL ON CLIMATE CHANGE, 2007). Uma parte do biogás gerado em aterros sanitários, composto por 50 a $60 \%$ de $\mathrm{CH}_{4}$, pode atravessar a barreira de cobertura e escapar para a atmosfera, mesmo no caso dos aterros dotados de sistema de captação de biogás. Os sistemas mais eficientes são capazes de captar $75 \%$ do biogás gerado em um aterro sanitário; entretanto, na maioria dos casos a eficiência está entre 40 e 60\% (BARLAZ et al, 2004).

O controle das emissões de metano em aterros pode ser realizado por meio da captação de biogás e combustão (flares), combustão com geração de energia (NIKIEMA; BRZEZINSKI; HEITZ, 2007) e por via biológica através da oxidação aeróbia nas coberturas dos aterros ou em biofiltros (WHALEN; REEBURGH; SANDBECK, 1990; BENDER; CONRAD, 1995; BOECKX; VAN CLEEMPUT; VILLARALVO, 1996; BARLAZ et al, 2004; HILGER; HUMER, 2003; NIKIEMA; BRZEZINSKI; HEITZ, 2007; EINOLA; KARHU; RINTALA, 2008). A oxidação do metano também foi constatada em ambientes anaeróbios (ZEHNDER; BROCK, 1980).

A oxidação biológica do gás metano acontece através da ação de bactérias metanotróficas que são capazes de utilizar o metano como fonte de carbono e energia, principalmente quando próximo à superfície, onde existe um aporte maior de oxigênio (PELMONT, 1993; HANSON; HANSON, 1996, MURREL; McDONALD; BOURNE, 1998, McDONALD et al, 2008). Esse fenômeno biológico se instala espontanemante e é dependente do fluxo de metano pela cobertura e do oxigênio presente (BENDER; CONRAD, 1995; BOGNER, 1995; KIGHTLEY; NEDWELL, 1995; BÖRJESSON; SVENSSON, 1997; BOECKX; VAN CLEEMPUT; VILLARALVO, 1996; BARLAZ et al, 2004; NIKIEMA; BRZEZINSKI; HEITZ, 2007; EINOLA; KARHU; RINTALA, 2008).

O gás metano que passa através da cobertura dos aterros de resíduos sólidos urbanos (RSU) é consumido pelas bactérias metanotróficas que o convertem em água, dióxido de carbono e biomassa celular, como mostra a reação da Equação 1.

$\mathrm{CH}_{4}+2 \mathrm{O}_{2} \Rightarrow \mathrm{CO}_{2}+2 \mathrm{H}_{2} \mathrm{O}$

Equação 1

A utilização do metano pelas bactérias metanotróficas como fonte de carbono e energia é possível devido à ação da enzima metano monoxigenase que oxida o metano produzindo metanol com geração de duas moléculas de água. O metanol produzido é transformado em formaldeido, o qual é depois assimilado em diferentes rotas (HANSON; HANSON, 1996).

Os microrganismos metanotróficos podem ser divididos em dois grupos fisiológicos distintos: tipo I e tipo II. O tipo I (Methylomonas, Methylocaldum, Methylosphaera, Methylomicrobium e Methylobacter) assimila o formaldeído produzido na oxidação do metano (via metanol) utilizando a rota da monofosfato ribulose. O tipo II (Methylocystis e Methylosinus) utiliza a rota da serina para a assimilação do formaldeído (HANSON; HANSON, 1996; MURREL; McDONALD; BOURNE, 1998; McDONALD et al, 2008).

O processo de oxidação biológica do metano depende de diferentes fatores físico-químicos, que envolvem tanto características geotécnicas quanto microbiológicas da cobertura. $\mathrm{Na}$ literatura, encontram-se informações sobre a importância do teor de umidade do solo de cobertura (ZEISS, 1996; BOECKX; VAN CLEEMPUT; VILLARALVO, 1996; VISVANATHAN, 1999; CHRISTOPHERSEN, 2001), e sobre a concentração de nutrientes e inibidores (KIGHTLEY; NEDWELL, 1995; BOGNER, 1995; VISVANATHAN, 1999).

Neste trabalho, apresentam-se informações geotécnicas e microbiológicas sobre os solos de cobertura de três aterros de RSU. Essas informações contribuem para o conhecimento da atividade metanotrófica nas coberturas de aterros de RSU e tem o objetivo de melhorar a eficiência desses sistemas de oxidação de metano.

\section{Material e métodos}

\section{Aterros amostrados}

As amostras foram coletadas no Aterro Sanitário de São Giácomo (Caxias do Sul, Rio Grande do Sul), célula experimental da Universidade de Caxias do Sul (UCS) e Aterro Bandeirantes (São Paulo).

O Aterro Sanitário Municipal de São Giácomo (SG) recebe os resíduos sólidos gerados no município de Caxias do Sul, exceto os encaminhados à coleta seletiva. O sistema de aterramento é do tipo celular em camadas de quatro metros. A célula escolhida entrou em operação em dezembro de 2004 e encerrou-se em março de 2006. Nesse período, foram dispostas cerca de 128 mil toneladas de resíduo. Os gases são drenados e queimados em flares.

A célula experimental da UCS fica localizada na Cidade Universitária, em Caxias do Sul. Trata-se de uma célula remanescente de um projeto de pesquisa iniciado em 2001. A célula foi monitorada ao longo de dois anos (2001 a 2003) produzindo dados sobre qualidade do líquido percolado e de água subterrânea coletada em poços de monitoramento (PESSIN et al, 2002). A célula experimental possui um queimador do tipo flare. 
O aterro sanitário Bandeirantes (AB) está localizado na Rodovia Bandeirantes, quilômetro 26, no estado de São Paulo. Encontra-se em operação desde 1978, totalizando cerca de 23 milhões de toneladas de resíduos aterrados. Diariamente, o aterro recebe a metade do resíduo gerado na cidade de São Paulo, o que equivale a 7 mil toneladas. O sistema de geração de energia com biogás implementado no aterro Bandeirantes é, atualmente, o maior do mundo, com a geração prevista em 170 mil MWh por ano. O local escolhido para obtenção das amostras recebeu sua cobertura final no ano 2000

\section{Coleta das amostras}

No aterro de São Giácomo e na célula experimental da UCS, obtiveram-se amostras nas profundidades de 5 e $15 \mathrm{~cm}$. Na cobertura do aterro Bandeirantes, as amostras foram obtidas a uma profundidade de $30 \mathrm{~cm}$. Nos três aterros, coletaram-se amostras indeformadas (ensaios geotécnicos) e deformadas (ensaios microbiológicos e físicoquímicos). As amostras indeformadas foram retiradas em anéis metálicos e as deformadas, com espátulas esterilizadas e acondicionadas em sacos plásticos herméticos (TORVES et al, 2007).

A escolha dos locais de amostragem no aterro sanitário de São Giácomo e na célula experimental da UCS foi realizada a partir da avaliação da saída de biogás pela cobertura, por meio do método da câmera estática. No caso do aterro de São Giácomo, uma célula foi escolhida para a realização do estudo (célula que foi operada entre dezembro de 2004 e março de 2006).

A câmera para a prospecção de biogás pela cobertura foi confeccionada em aço inox e acrílico e montada pelo Laboratório de Tecnologia e Pesquisa da UCS, baseado em Maciel e Jucá (2002). A câmera possui $10 \mathrm{~cm}$ de altura e $60 \mathrm{~cm}$ de largura, com um volume interno de oito litros. A câmera foi cravada no solo de forma a captar o biogás que passa através da cobertura e permitir a análise de sua composição sem a interferência dos gases da atmosfera, conforme apresentado na Figura 1. Os gases foram analisados com um analisador de gás portátil Dräger X-am 7000, que permite a análise simultânea e contínua de $\mathrm{CO}_{2}, \mathrm{O}_{2}, \mathrm{H}_{2} \mathrm{~S}$ e $\mathrm{CH}_{4}$. No aterro de São Giácomo, foram obtidas seis amostras (três pontos de amostragem e duas profundidades), e na célula experimental da UCS, quatro amostras nas duas profundidades mencionadas. As amostras foram coletadas no aterro de São Giácomo em junho 2006 (amostra SG1), julho de 2006 (amostra SG2) e setembro de 2006 (amostra SG3). No aterro experimental UCS, as amostras foram coletadas em março de 2006 (amostra UCS1) e agosto de 2006 (amostra UCS2).

No aterro Bandeirantes a escolha do local foi feita com base na idade do aterro (cinco anos), sem medição prévia das concentrações de biogás na superfície (TEIXEIRA, 2008). Um bloco indeformado e amostras deformadas foram obtidos na profundidade de $30 \mathrm{~cm}$. A coleta dessa amostra foi feita em maio de 2005.

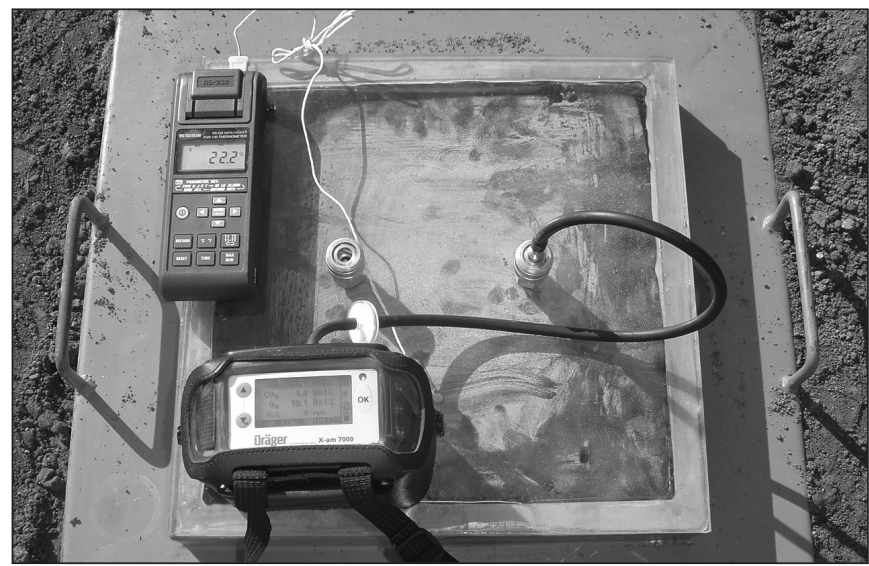

Figura 1 - Câmera estática e demais equipamentos usados para detectar a presença de biogás através da cobertura

\section{Caracterização geotécnica e físico-química das amostras}

As amostras de solo da cobertura dos aterros foram caracterizadas em relação aos seguintes parâmetros geotécnicos: granulometria (ASSOCIAÇÃO BRASILEIRA DE NORMAS TÉCNICAS, 1984D), limites físicos (ASSOCIAÇÃO BRASILEIRA DE NORMAS TÉCNICAS, 1984A; 1984C), e densidade relativa dos grãos (ASSOCIAÇÃO BRASILEIRA DE NORMAS TÉCNICAS, 1984B). Com relação às condições de campo, foram determinados os seguintes parâmetros: teor de umidade, índice de vazios e grau de saturação.

Nas amostras foram determinados o pH e o teor de sólidos totais voláteis pelos métodos potenciométrico e gravimétrico, respectivamente.

\section{Contagem e isolamento de bactérias metanotróficas e avaliação de consumo de metano}

As amostras foram preparadas em capela de fluxo laminar e incubadas em bancada de incubação que permite o estabelecimento de atmosfera ideal para o crescimento do microrganismo. A montagem da bancada para incubação das bactérias metanotróficas foi realizada pelo Laboratório de Tecnologia e Pesquisa (LTPE-UCS) e seguiu o modelo proposto por Fornés, Ott e Jager (2003). A bancada de incubação é constituída basicamente de um dessecador conectado a uma bomba de vácuo modelo 355B2 da marca Quimis Aparelhos Científicos Ltda., ligado a um vacuômetro digital modelo Gul Press 100 marca Gulton e um sistema de distribuição de gases. Os gases utilizados foram: dióxido de carbono ( $\mathrm{CO}_{2}$ Grau de pureza 99,97\% fornecedor Air Products Brasil Ltda.), metano $\left(\mathrm{CH}_{4}\right.$ Grau de pureza 99\% fornecedor Air Porducts Ltda.) e ar sintético (superseco fornecedor Air Products Brasil Ltda.). O ar sintético é composto de 20 $\pm 0,5 \%$ de oxigênio, máximo de 3 ppm de água e nitrogênio até completar 
$100 \%$. Os cilindros contendo esses gases foram conectados ao sistema de distribuição com válvulas agulha individuais. Na Figura 2 está apresentado um esquema do sistema utilizado. No interior do dessecador, foi instalado um termostato para controle de temperatura, como mostra a Figura 2. Na bancada foram incubados tanto os tubos para contagem de número mais provável (NMP), como as placas para isolamento dos microrganismos. A criação da atmosfera modificada foi feita por substituição da atmosfera dentro do dessecador, iniciando com estabelecimento de vácuo e posterior injeção de $\mathrm{CO}_{2}$ seguida de $\mathrm{CH}_{4}$ e, finalmente, ar sintético, até a pressão atmosférica, com auxílio do vacuômetro (Figura 2). Partindo-se do vácuo estabelecido, introduziu-se o $\mathrm{CO}_{2}$ aumentando a pressão em $30 \%$, seguido de aumento até $60 \%$ para o $\mathrm{CH}_{4}$ e $10 \%$ para o ar sintético, chegando-se à pressão atmosférica.

O procedimento de cultivo e inoculação foi realizado pesando-se $5 \mathrm{~g}$ de solo in natura e transferindo-se essa quantidade para frascos contendo $45 \mathrm{~mL}$ de meio mineral amônia líquido (FORNÉS; OTT; JAGER, 2003). Sucessivas diluições foram realizadas até obter-se uma concentração de $10^{-6}$. Cinco réplicas foram preparadas para cada diluição. Para o isolamento dos microrganismos obtidos na contagem NMP, foi preparado meio mineral amônia sólido, acrescentando-se $14 \mathrm{~g}$ de ágar por litro. Para controle do crescimento de bactérias metanotróficas, incubou-se um controle negativo (composto por meio mineral sem inoculação) e um controle positivo (meio mineral inoculado com Methylococcus capsulatus cepa ATCC $^{\circledR} n^{\circ}$ 19069). Os tubos

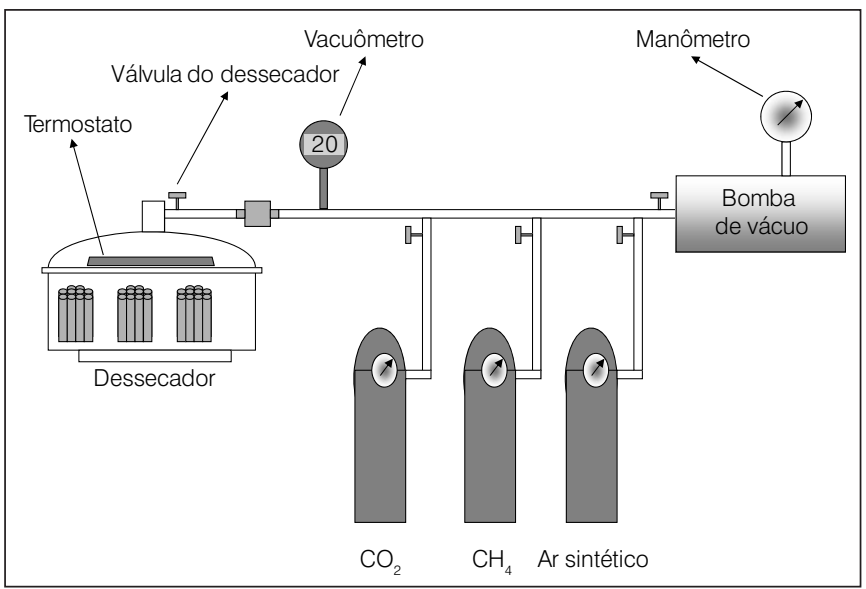

Figura 2 - Esquema da bancada de incubação em atmosfera modificada

Tabela 1 - Limites físicos e densidade relativa dos grãos

\begin{tabular}{lcccc} 
Amostra & Profundidade $(\mathrm{cm})$ & $\mathrm{W}_{\mathrm{I}}$ & $\mathrm{W}_{\mathrm{p}}$ & $\mathrm{G}_{\mathrm{s}}$ \\
\multirow{2}{*}{$\mathrm{SG}$} & 5 & 63 & 42 & 2.66 \\
& 15 & 63 & 44 & 2.66 \\
\multirow{2}{*}{ UCS } & 5 & 61 & 43 & 2.54 \\
$\mathrm{AB}$ & 15 & 64 & 45 & 2.68 \\
\hline
\end{tabular}

$\mathrm{W}_{\mathrm{l}}$ : limite de liquidez (\%); $\mathrm{W}_{\mathrm{p}}$ : limite de plasticidade (\%); $\mathrm{G}_{\mathrm{s}}$ : densidade relativa dos grãos; SG: aterro sanitário municipal de São Giácomo; UCS: aterro sanitário da Universidade de Caxias do Sul; AB: aterro sanitário Bandeirantes. foram incubados a $35^{\circ} \mathrm{C}$ dentro do dessecador por 48 dias. Os resultados da contagem foram comparados aos valores presentes na tabela de NMP apresentados em Man (1977). Os tubos considerados positivos foram aqueles que apresentaram turbidez no meio, formação de uma membrana de cor branca a amarelada na superfície do meio de cultivo e formação de um sedimento no fundo do frasco.

Para a caracterização morfológica, selecionaram-se de três a quatro séries de diluições positivas, inoculando-as em meio mineral amônia sólido. O estudo da morfologia colonial considerou os seguintes aspectos: tamanho, forma, elevação, cor, superfície, densidade e consistência. As células foram observadas a partir do microscópio modelo Axiolab, marca Carl Zeiss, com máquina digital acoplada, com contraste de fase, marca Kocoda e modelo Color CCD, para identificação morfológica das células (forma e arranjo), observação de cistos e esporos e resultado na coloração de Gram.

A avaliação do consumo de metano e produção de gás carbônico foi realizada em laboratório, utilizando-se frascos do tipo antibiótico de $50 \mathrm{~mL}$ fechados com batoques de teflon e lacrados com selo de alumínio. Nos frascos, foram introduzidos $4,5 \mathrm{~mL}$ do meio mineral amônia, sem fonte de carbono, misturados a $0,5 \mathrm{~mL}$ da amostra, realizando-se cinco réplicas para cada amostra. A mudança da atmosfera nos frascos foi realizada com os frascos já inoculados, nos quais foram introduzidos $45 \mathrm{~mL}$ de gás metano $\left(\mathrm{CH}_{4} \mathrm{Grau}\right.$ de pureza 99\%, fornecido pela empresa Air Products Ltda.), o qual se misturou com o ar atmosférico dentro dos frascos. Esse procedimento foi realizado para uma amostra de cada aterro na profundidade de $5 \mathrm{~cm}$ e para a amostra de $30 \mathrm{~cm}$ do aterro Bandeirantes. As determinações das concentrações de metano e dióxido de carbono foram realizadas em triplicata, através da injeção de 1,0 mL da amostra da atmosfera do frasco (headspace) em um cromatógrafo gasoso devidamente calibrado, modelo Auto System XL marca Perkin Elmer equipado com coluna empacotada Poropak N80/100 Mesh com dimensões de 6’x1/8" OD NickelPacked, e detector de condutividade térmica (TCD). As leituras foram realizadas após 7 , 14, 27 e 48 dias de incubação.

\section{Resultados e discussão}

\section{Características geotécnicas das amostras}

Os solos coletados no aterro experimental da UCS e no aterro sanitário de São Giácomo apresentaram características semelhantes com relação aos limites físicos o que diferiram do aterro Bandeirantes. Na Tabela 1 estão apresentados os limites físicos dos solos e a densidade relativa dos grãos das coberturas.

Na Figura 3 estão apresentadas as curvas granulométricas obtidas para os solos dos locais ensaiados. O solo da cobertura do aterro São Giácomo e UCS são compostos por argila de alta plasticidade $(\mathrm{CH})$; já o solo da cobertura do aterro Bandeirantes classifica-se 


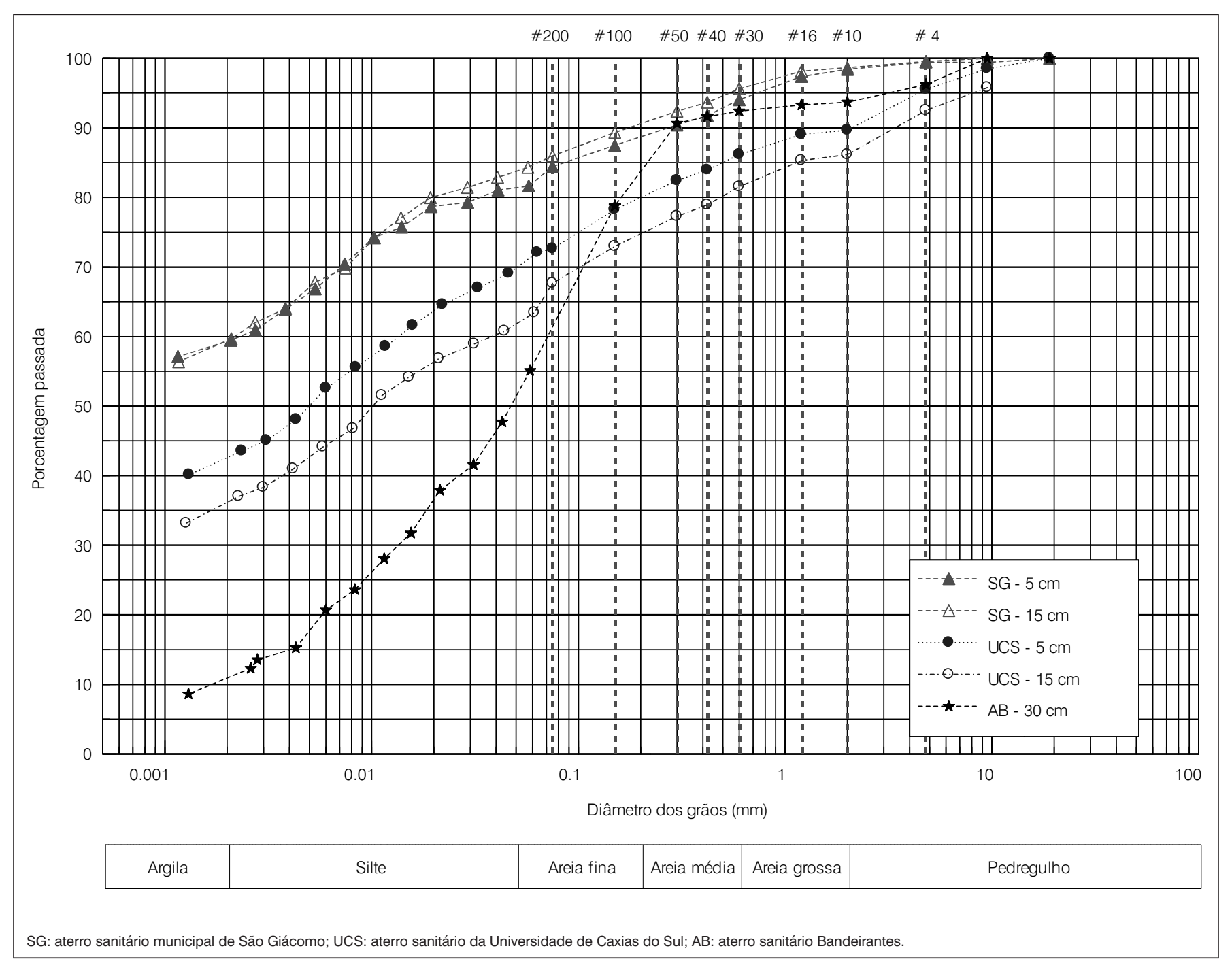

Figura 3 - Curvas granulométricas dos solos coletados

como um silte de baixa plasticidade (ML), segundo a classificação unificada de solos.

Os parâmetros de estudo das amostras utilizadas para a determinação da curva de retenção no momento da amostragem estão apresentados na Tabela 2 .

O índice de vazios e o grau de saturação afetam o fluxo de gás pela camada de cobertura. O transporte dos gases no perfil é fundamental para o desenvolvimento dos microrganismos metanotróficos que dependem do metano presente no biogás gerado no interior do aterro e do oxigênio que penetra no perfil a partir da atmosfera. Solos com poros menores, além de representarem uma redução na permeabilidade ao gás se mantêm com um grau de saturação elevado.

Na Figura 4 estão apresentados os resultados obtidos durante os ensaios para a determinação da curva de retenção. A curva de retenção representa a relação entre a quantidade de água retida no solo e a sucção gerada pela estrutura porosa do material. Na Figura 4A tem-se a variação do índice de vazios com o aumento da sucção devido ao
Tabela 2 - Índices físicos das amostras analisadas

\begin{tabular}{lcccc} 
Amostra & Profundidade $(\mathrm{cm})$ & $\mathrm{e}$ & W (\%) & $\mathrm{S}(\%)$ \\
\hline SG1 & 5 & 1,324 & 25,7 & 52 \\
\hline SG1 & 15 & 0,941 & 30,7 & 87 \\
SG2 & 5 & 0,903 & 25,7 & 76 \\
\hline SG2 & 15 & 0,642 & - & - \\
SG3 & 5 & 1,113 & 25,7 & 61 \\
\hline SG3 & 15 & 0,791 & 28,2 & 95 \\
UCS1 & 5 & 1,430 & 34,0 & 60 \\
UCS1 & 15 & 1,480 & 44,0 & 80 \\
UCS2 & 5 & 1,450 & 52,0 & 91 \\
UCS2 & 15 & 1,470 & 43,0 & 78 \\
\hline AB & 30 & 0,930 & 20,7 & 61 \\
\hline
\end{tabular}

e: índice de vazios; W: teor de umidade; S: grau de saturação; SG1: amostra coletada do aterro de São Giácomo em junho de 2006; SG2: amostra coletada do aterro de São Giácomo em julho de 2006; SG3: amostra coletada do aterro de São Giácomo em setembro de 2006; UCS1: amostra coletada do aterro experimental da Universidade de Caxias do Sul em março de 2006; UCS2: amostra coletada do aterro experimental da Universidade de Caxias do Sul em agosto de 2006; AB: aterro sanitário Bandeirantes. 


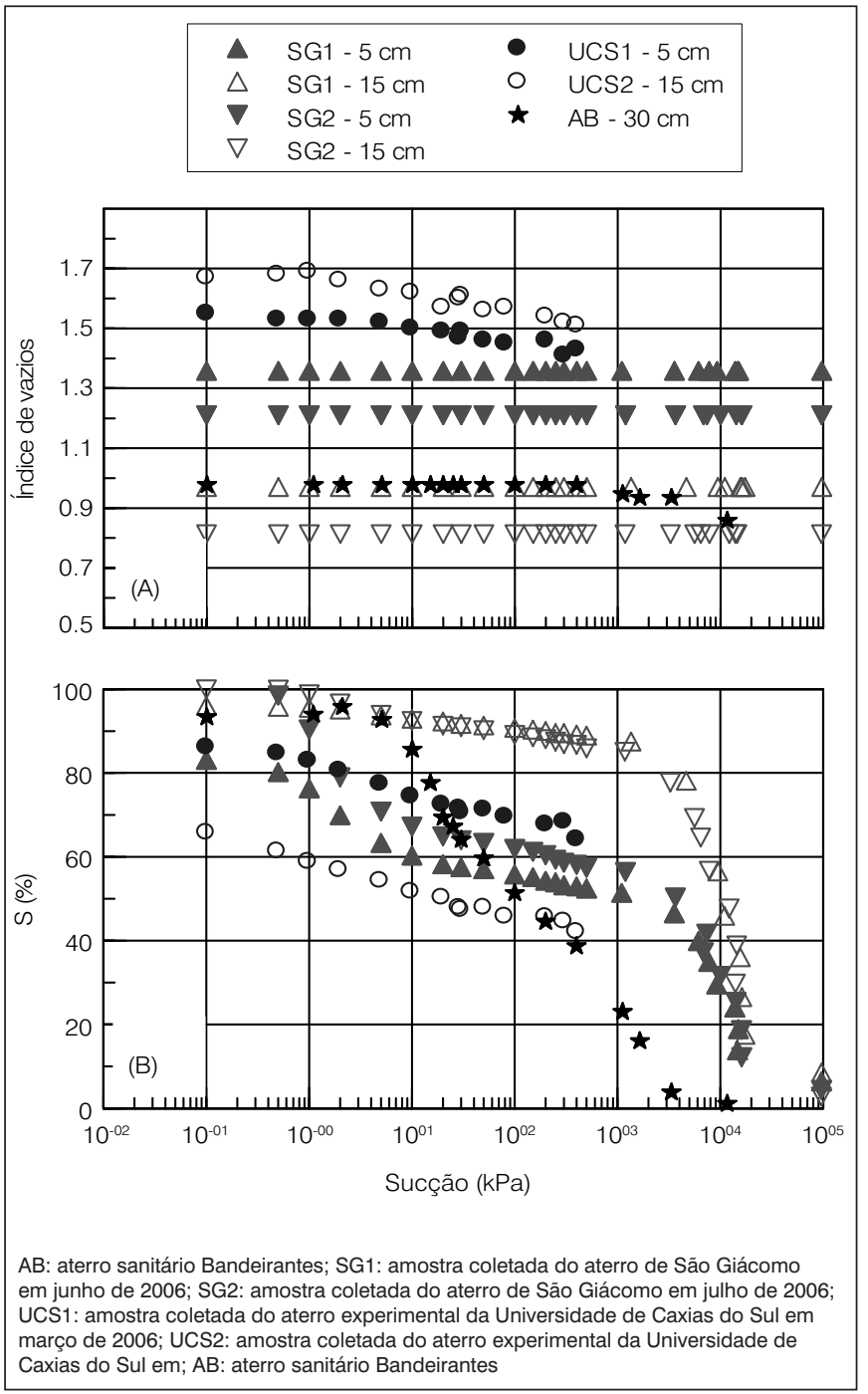

Figura 4 - Resultados da determinação da curva de retenção de água dos solos

Tabela 3 - Resultados das determinações dos parâmetros químicos das amostras coletadas nos Aterros de São Giácomo e célula experimental UCS

\begin{tabular}{lccc} 
Amostra & Profundidade $(\mathrm{cm})$ & $\mathrm{pH}$ & $\mathrm{STV}(\%)$ \\
\hline SG1 & 5 & 5 & 11,2 \\
SG1 & 15 & 4,7 & 12,2 \\
\hline SG2 & 5 & 4,3 & 11,7 \\
\hline SG2 & 15 & 4,5 & 11,7 \\
\hline SG3 & 5 & 4,5 & 15,2 \\
\hline SG3 & 15 & 5,4 & 12,9 \\
\hline UCS1 & 5 & 4,5 & 15,7 \\
\hline UCS1 & 15 & 4,5 & 13,2 \\
\hline UCS2 & 5 & 4,7 & 13,5 \\
UCS2 & 15 & 4,5 & 14,3 \\
\hline AB & 30 & 3,5 & 0,6
\end{tabular}

STV: sólidos totais voláteis; SG1: amostra coletada do aterro de São Giácomo em junho de 2006; SG2: amostra coletada do aterro de São Giácomo em julho de 2006; SG3: amostra coletada do aterro de São Giácomo em setembro de 2006; UCS1: amostra coletada do aterro experimental da Universidade de Caxias do Sul em março de 2006; UCS2: amostra coletada do aterro experimental da Universidade de Caxias do Sul em agosto de 2006; AB: aterro sanitário Bandeirantes. processo de secagem induzido pelo ensaio. Observa-se que apenas o solo da cobertura da célula experimental da UCS apresentou alguma redução de índice de vazios com o aumento da sucção. Na Figura 4B apresenta-se a variação do grau de saturação com o aumento da sucção. O solo da cobertura do aterro de SG, na profundidade de 15 cm, mantém-se com um elevado grau de saturação (> 90\%) até valores altos de sucção. Os demais solos apresentaram baixa saturação (<80\%) para sucções da ordem de $10 \mathrm{kPa}$. A manutenção do grau de saturação elevado inibe o fluxo de biogás pela camada de cobertura. Solos que dessaturam com baixos valores de sucção permitem, em geral, maior fluxo de gás através da cobertura.

\section{Análises químicas}

Os resultados das análises químicas estão apresentados na Tabela 3 e referem-se à média das triplicatas. $\mathrm{O}$ pH das amostras de solo situa-se entre 5,4 e 3,5. Segundo estudos de Dedysh, Panikov e Tiedje (1998) o pH ótimo para o desenvolvimento das bactérias metanotróficas varia de 4,5 a 5,5; portanto, as amostras estudadas estão na faixa considerada ótima para esse parâmetro, com exceção da amostra $\mathrm{AB}$ que ficou inferior $(3,5)$.

Os sólidos totais voláteis apresentaram valores muito semelhantes para os perfis SG1, e SG2, variando de 11,2 a 12,2\%. Já no perfil SG3, para a amostra obtida a $5 \mathrm{~cm}$, o valor foi de $15,2 \%$. Para o solo da célula experimental da UCS os valores variaram entre 13,2 e $15,7 \%$. O solo da cobertura do aterro bandeirante apresentou o menor valor de $\mathrm{pH}$ e a menor quantidade de matéria orgânica em relação às amostras dos demais aterros. A presença da matéria orgânica aumenta a porosidade do solo, beneficiando o processo de oxidação (ZEISS, 1996; CHRISTOPHERSEN, 2001).

\section{Avaliação do crescimento das bactérias metanotróficas e sua relação com os parâmetros físicos do solo}

O resultado da contagem de bactérias por NMP é apresentado na Tabela 4, assim como a descrição das células microbianas observadas em microscopia óptica com coloração de Gram, obtida nos diferentes tubos de contagem que apresentaram resultados positivos

A contagem de NMP variou de valores da ordem de $10^{-3}$ até $10^{-8}$. Dentre as amostras SG, o ponto SG1 apresentou valores superiores aos obtidos para SG2 e SG3 nas duas profundidades. Essa contagem mais alta do que as demais pode estar relacionada à distribuição do metano na cobertura do aterro SG, às condições climáticas no período de amostragem, entre outros. Como é um aterro muito grande com sistema de coleta de gases, o metano pode se distribuir de forma diferente nas células e, consequentemente, na cobertura em função da proximidade com o sistema de drenagem de gases e de sua eficiência. As outras amostras SG apresentaram os menores valores de 
contagem (ordem de 10-3) comparadas às amostras do UCS e do AB, que apresentaram valores na ordem de $10^{-4}$ e $10^{-5}$, respectivamente.

Todas as amostras foram semelhantes em relação às morfologias celulares encontradas: bacilos e cocos Gram-negativos. A cepa padrão apresentou células Gram-negativas encapsuladas e possuindo arranjo característico de diplococos.

No isolamento das colônias em placas, a partir dos tubos de contagem, a cepa padrão (ATCC ${ }^{\circledR} \mathrm{n}^{\circ}$ 19069) apresentou colônias lisas, inteiras e reluzentes em meio sólido. Nas amostras SG, as colônias encontradas apresentavam cor amarela e tamanho superior a $1 \mathrm{~mm}$ de diâmetro), irregulares e opacas. Nas amostras provenientes do aterro da UCS, observaram-se colônias espraiadas opacas, amarelas e grandes (> $1 \mathrm{~mm}$ de diâmetro), colônias circulares, de bordo liso, opacas, pretas e grandes (> $1 \mathrm{~mm}$ de diâmetro). No caso das amostras provenientes do $\mathrm{AB}$, observaram-se colônias amarelas circulares e grandes (> $1 \mathrm{~mm}$ de diâmetro). Algumas colônias apresentaram morfologia semelhante à cepa padrão, bem como suas células. Estudos realizados por Liotti (2007) a partir de métodos moleculares, identificaram bactérias metanotróficas nas amostras do $A B$ pertencentes à Família Methylocystaceae do gênero Methylocystis. As amostras SG que apresentaram maior contagem não mostraram maior diversidade morfológica de bactérias. Por outro lado, aquelas que apresentaram a contagem mais baixa mostraram apenas bacilos Gram-negativos. A amostra UCS1/15 apresentou a maior diversidade morfológica de bactérias, apesar de ter apresentado uma contagem de NMP intermediária com relação às outras amostras. Não foi realizada uma contagem de número de diferentes colônias para cada amostra.

A Figura 5 apresenta os resultados das contagens em NMP em função da profundidade (Figura 5A) e em relação ao grau de saturação (Figura 5B) no momento da coleta das amostras. Conforme ilustrado na Figura 5A, não é possível concluir que existe uma relação entre o aumento do NMP com a profundidade, porém observou-se que o solo do aterro de São Giácomo (SG1) apresentou o maior valor de NMP/g de solo seco, seguido do aterro dos Bandeirantes (AB). Não se observou uma relação entre o número de células e o índice de vazios das amostras.

Na Figura 5B, é apresentada a relação entre o número de células por grama de solo seco em função do grau de saturação no momento da coleta das amostras. Como um grau de saturação induz uma maior permeabilidade ao gás e a passagem do gás é um dos fatores que favorecem o desenvolvimento das bactérias, a relação entre o grau de saturação e a quantidade de células pode ser regida por esse fator conforme se observa na Figura 5B. Com exceção do solo de uma amostra do SG1, obtido a $15 \mathrm{~cm}$ de profundidade (amostra SG1/15), os demais sugerem uma tendência de aumento da quantidade de células inversamente proporcional ao grau de saturação.

De acordo com Humer e Lechner (1999), um horizonte de 10 e $30 \mathrm{~cm}$ é a região de maior conversão de metano. Para Visvanathan (1999), esse horizonte fica entre 15 e 40 cm. Essas observações
Tabela 4 - Enumeração de tubos positivos NMP nas amostras coletadas nos três aterros

\begin{tabular}{|c|c|c|}
\hline Amostras & $\begin{array}{l}\text { NMP/g de solo } \\
\text { (base seca) }\end{array}$ & $\begin{array}{l}\text { Observação microscópica } \\
\text { da amostra }\end{array}$ \\
\hline SG1/5 & $1,4 \times 10^{7}$ & Cocos e bacilos Gram-negativos \\
\hline SG1/15 & $\geq 1,6 \times 10^{8}$ & Cocos e bacilos Gram-negativos \\
\hline SG2/5 & $5,0 \times 10^{3}$ & Cocos e bacilos Gram-negativos \\
\hline SG2/15 & $2,6 \times 10^{3}$ & Cocos e bacilos Gram-negativos \\
\hline SG3/5 & $3,0 \times 10^{3}$ & Bacilos Gram-negativos \\
\hline SG3/15 & $2,3 \times 10^{3}$ & Bacilos Gram-negativos \\
\hline UCS $1 / 5$ & $1,7 \times 10^{4}$ & Bacilos e cocos Gram-negativos \\
\hline UCS1/15 & $2,1 \times 10^{4}$ & $\begin{array}{l}\text { Bacilos, cocobacilos Gram-negativos } \\
\text { e cocos Gram-positivos }\end{array}$ \\
\hline UCS2/5 & $1,7 \times 10^{3}$ & Bacilos e cocos Gram-negativos \\
\hline UCS2/15 & $1,2 \times 10^{3}$ & Bacilos e cocos Gram-negativos \\
\hline $\mathrm{AB}$ & $3,3 \times 10^{5}$ & Bacilos encapsulados Gram-negativos \\
\hline
\end{tabular}

SG1/5: amostra coletada do aterro de São Giácomo em junho de 2006 a $5 \mathrm{~cm}$ de profundidade; SG1/15: amostra coletada do aterro de São Giácomo em junho de 2006 a $15 \mathrm{~cm}$ de profundidade; SG2/5: amostra coletada do aterro de São Giácomo em julho de 2006 a $5 \mathrm{~cm}$ de profundidade; SG2/15: amostra coletada do aterro de São Giácomo em julho de 2006 a $15 \mathrm{~cm}$ de profundidade: SG3/5: amostra coletada do aterro de São aterro de São Giácomo em setembro de 2006 a $15 \mathrm{~cm}$ de profundidade; UCS1/5: amostra aterro de São Giácomo em setembro de 2006 a $15 \mathrm{~cm}$ de profundidade; UCS1/5: amostra $\mathrm{cm}$ de profundidade; UCS1/15: amostra coletada do aterro experimental da Universidade de Caxias do Sul em março de 2006 a $15 \mathrm{~cm}$ de profundidade; UCS2/5: amostra coletada do aterro experimental da Universidade de Caxias do Sul em agosto de 2006 a $5 \mathrm{~cm}$ de profundidade; UCS2/15: amostra coletada do aterro experimental da Universidade de Caxias do Sul em agosto de 2006 a $15 \mathrm{~cm}$ de profundidade.
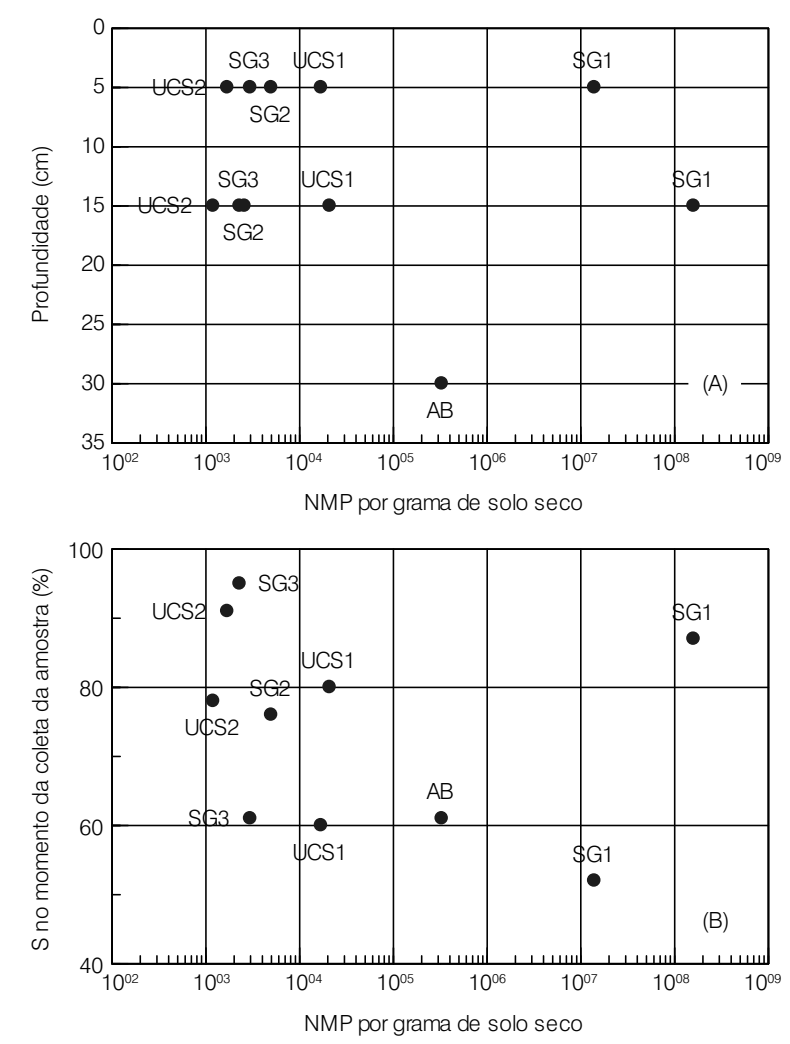

SG1: amostra coletada do aterro de São Giácomo em junho de 2006; SG2: amostra coletada do aterro de São Giácomo em julho de 2006; SG3: amostra coletada do aterro de São Giácomo em setembro de 2006; UCS1: amostra coletada do aterro experimental da Universidade de Caxias do Sul em março de 2006; UCS2: amostra coletada do aterro experimental da Universidade de Caxias do Sul em agosto de 2006; AB: aterro sanitário Bandeirantes; NMP: número mais provável

Figura 5 - Número mais provável por grama de solo seco em função da profundidade e grau de saturação (A) Profundidade (B) Grau de saturação das amostras 


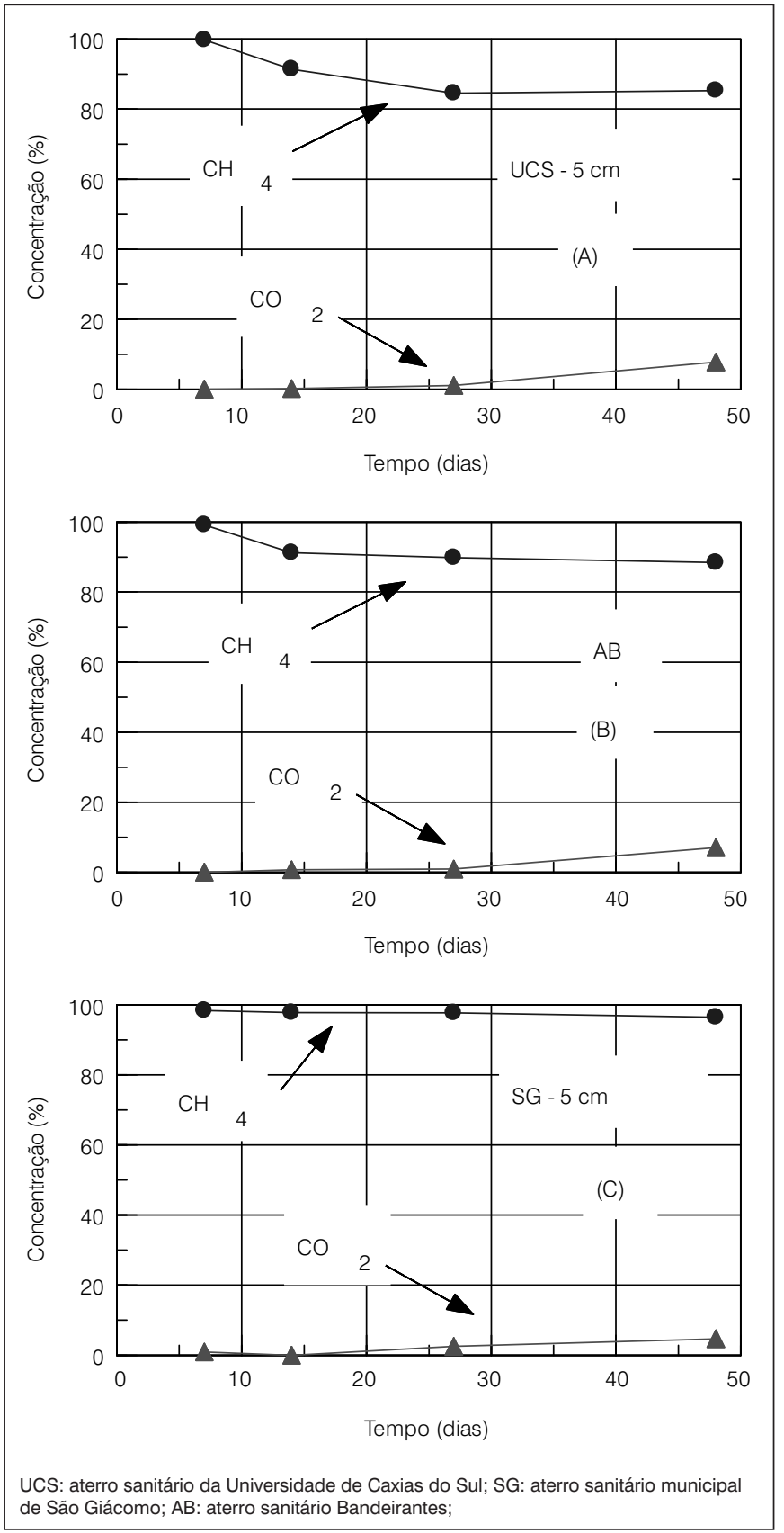

Figura 5 - Resultados do consumo de metano e geração de gás carbônico: (A) UCS $5 \mathrm{~cm}$ (B) AB (C) $S G 5 \mathrm{~cm}$

justificam, em parte, os valores constantes obtidos na maioria das amostras. Os autores anteriormente citados não apresentaram as estimativas do número de microrganismos encontrados.

\section{Avaliação do consumo de metano em laboratório}

Na Figura 5 estão apresentados os resultados obtidos do consumo de metano de amostras da cobertura dos três aterros.
Os dados referem-se às amostras obtidas a $5 \mathrm{~cm}$ para os aterros de São Giácomo e UCS e para a amostra obtida a $30 \mathrm{~cm}$ no aterro Bandeirantes. As amostras foram monitoradas por 48 dias. São apresentados os valores das concentrações de metano e dióxido de carbono para os diferentes tempos.

A amostra que apresentou maior consumo de metano foi do aterro UCS, com valores na faixa de $80 \%$ seguida de $A B$ e de SG que apresentaram valores da ordem de $90 \%$. Todas as amostras demonstraram a mesma tendência ao consumo de metano ao longo do tempo, acompanhada da tendência ao aumento do gás carbônico.

Embora o consumo observado do metano seja relativamente baixo para os tempos monitorados, considera-se que há atividade metanotrófica no sistema. Salienta-se que o nível de consumo observado neste experimento não reflete necessariamente o consumo de campo, onde as condições são distintas, mas indica a atividade das bactérias metanotróficas, pois houve geração de dióxido de carbono e diminuição da concentração de metano.

\section{Conclusões}

As amostras dos três aterros estudados apresentaram crescimento positivo de microrganismos metanotróficos. Não foi observada, para as amostras analisadas, qualquer relação do número de microrganismos com a profundidade.

Os resultados deste estudo sugerem que existe uma relação entre o estado do solo (representado pelo grau de saturação) e o desenvolvimento de bactérias metanotróficas. Observou-se um aumento da contagem de NMP inversamente proporcional ao grau de saturação das amostras, o que interfere na permeabilidade aos gases metano e oxigênio, necessários ao metabolismo dos microorganismos na camada de cobertura. Nos ensaios de consumo realizados em laboratório, observou-se um baixo consumo de metano para o tempo monitorado.

O aprofundamento dos estudos deve ser feito para avaliar a oxidação biológica nas diversas épocas do ano, nas quais existirão variações do grau de saturação e, consequentemente, do fluxo de gás. A instalação de coberturas eficientes na conversão de metano deve contribuir para a redução da emissão de metano dos aterros de resíduos sólidos urbanos.

\section{Agradecimentos}

Os autores agradecem pela valiosa colaboração dos seguintes pesquisadores: Professor Alexandre Cabral e Professora Rosana Vazoller e Ravhena Liotti. Os autores agradecem, também, o apoio financeiro do Ministério da Educação e Cultura, Secretaria de Educação Superior do Programa de Apoio a Núcleos de Excelência do Rio de Janeiro (Pronex-Rio) e Conselho Nacional de Desenvolvimento Científico e Tecnológico (CNPq). 


\section{Referências}

ASSOCIAÇÃO BRASILEIRA DE NORMAS TÉCNICAS. NBR 6459, Solo Determinação do limite de liquidez. Rio de Janeiro, 1984A.

NBR 6508, Massa específica - Grãos de solo que passam na peneira de 4,8 mm: Determinação da massa especifica. Rio de Janeiro, 1984B.

NBR 7180, Solo - Determinação do limite de plasticidade. Rio de Janeiro, 1984C

NBR 7181, Solo - Análise Granulométrica. Rio de Janeiro, 1984D.

BARLAZ, M.A. et al. Evaluation of a biologically active cover for mitigation of landfill gas emissions. Environmental Science \& Technology, v. 38, n. 18, p. 4891-4899, set. 2004

BENDER, M.; CONRAD, R. Effect of $\mathrm{CH}_{4}$ concentrations and soil conditions on the induction of $\mathrm{CH}_{4}$ oxidation activity. Soil Biology \& Biochemistry, v. 27, n. 12, p. 1517-1527, dez. 1995.

BOECKX, P.; VAN CLEEMPUT, O.; VILLARALVO, I. Methane emission from a landfill and the methane oxidising capacity of its covering soil. Soil Biology \& Biochemistry, v. 28, n. 10-11, p. 1397-1405, out./nov. 1996.

BOGNER, J. et al. Landfills as Atmospheric Methane Sources and Sinks. Chemosphere, v. 31, n. 9, p. 4119-30, nov. 1995.

BÖRJESSON, G.; SVENSSON, B.H. Seasonal and diurnal methane emissions from a landfill and their Regulation by methane oxidation. Waste Management and Research, v. 15, n. 1, p. 33-54, fev. 1997.

CHRISTOPHERSEN, M. Lateral gas transport in soil adjacent to an old landfill: factors governing emissions and methane oxidation. Waste Management and Research. v. 19, p. 126-143, 2001.

DEDYSH, S.N.; PANIKOV, N.; TIEDJE J.M. Acidophilic Methanotrophic communities from Sphagnum Peat Bogs. Applied and Environmental Microbiology, v. 64, p. 922-929, mar. 1998

EINOLA, J-K.M.; KARHU, A.E.; RINTALA, J.A. Mechanically-biologically treated municipal solid waste as a support medium for microbial methane oxidation to mitigate landfill greenhouse emissions. Waste Management, v. 28, n. 1 , p. $97-111$, jan. 2008

FORNÉS, L.; OTT, C.; JAGER, J. Development of a landfill cover with capillary barrier for methane oxidation - Methane oxidation in a compost layer. In: INTERNATIONAL WASTE MANAGEMENT AND LANDFILL SYMPOSIUM, 9, 2003, Sardinia. Proceedings... Sardinia, Italy: CISA, 2003, p. 167-168.

HANSON, R.S.; HANSON, T.E. Methanotrophic bacteria. Microbiological Reviews, v. 60, n. 2, p. 439-471, jun. 1996

HILGER, H.; HUMER, M. Biotic landfill cover treatments for mitigating methane emissions. Environmental Monitoring and Assessment, v. 84, n. 1-2, p. 71-84, mai. 2003
HUMER, M.; LECHNER, P. Alternative approach to the elimination of greenhouse gases from old landfills. Waste Management Research, v. 17, p. 443-452, dez. 1999.

INTERGOVERNMENTAL PANEL ON CLIMATE CHANGE. Fifth assessment report of the intergovernmental panel on climate change. Cambridge: Cambridge University Press, 2007.

KIGHTLEY, D.; NEDWELL, D.B. Capacity for methane oxidation in landfill cover soils measured in laboratory-scale soil microcosm. Applied and Environmental Microbiology, v. 61, n. 2, p. 592-601, fev. 1995.

LIOTTI, R.G. Verificação de procariontes metanotróficos em amostras ambientais através da determinação do potencial de oxidação do metano e da caracterização de culturas enriquecidas. 2007. 98 f. Dissertação (Mestrado em Microbiologia) - Instituto de Ciências Biomédicas da Universidade de São Paulo, São Paulo, 2007.

MACIEL, J.F.; JUCÁ, J.F.T. Gases monitoring methodology applied im Muribeca solid waste landfill. In: INTERNATIONAL CONGRESS ON ENVIRONMENTAL GEOTECHNICS, 4, 2002, Rio de Janeiro. Proceedings... Lisse: A.A. Balkema Publishers, 2002. v. 1, p. 263269.

MAN, J.C. MPN Tables for more than one test. European Journal of Applied Microbiology, v. 4, p. 307-316. dez. 1977.

McDONALD, I.R. et al. Molecular ecology techniques for the study of aerobic methanotrophs. Applied and Environmental Microbiology, v. 74, n. 5, p. 1305-15, mar. 2008.

MURREL, J.C.; McDONALD, I.R.; BOURNE, D.G. Molecular Methods for the study of methanotroph ecology. FEMS Microbiology Ecology , v. 27 n. 2, p. 103-14, out. 1998.

NIKIEMA, J.; BRZEZINSKI, R.; HEITZ, M. Elimination of methane generated by biofiltration: a review. Reviews in Environmental Science and Biotechnology, v. 6, n. 4, p. 261-84, out. 2007.

PELMONT, J. Bactéries et Environnement: adaptations physiologiques. 1 ed. Grenoble, Presses Universitaires de Grenoble, 1993. Collection Grenoble Sciences.

PESSIN, N. et al. Concepção e implantação de células piloto de aterramento de resíduos sólidos. In: CASTILHOS JUNIOR, A.B. et al. LIXO: alternativas de disposição de resíduos sólidos urbanos para pequenas comunidades. $1^{a}$ ed. São Carlos, São Paulo: RiMa Artes e Textos, 2002. Coletânea de Trabalhos Técnicos, v.3, p. 13-17.

TEIXEIRA, P.F. Oxidação biológica do metano em coberturas de aterros de resíduos sólidos urbanos: dinâmica do processo e aspectos geotécnicos. 2008. 164 f. Tese (Doutorado em Engenharia Civil) - Escola Politécnica da Universidade de São Paulo, São Paulo, 2008.

TORVES, J.C. et al. Oxidação biológica de metano em cobertura de aterro sanitário. In: CONGRESSO BRASILEIRO DE ENGENHARIA SANITÁRIA E AMBIENTAL, 24, 2007, Belo Horizonte. Anais... Belo Horizonte: Abes, 2007. 1 CD ROM 
VISVANATHAN, C. Methanotrophic activies in tropical landfill cover soils: effects of temperature, moisture content and methane concentration. Waste Management and Research, v. 17, p. 313-323, ago. 1999.

WHALEN, S.C.; REEBURGH, W.S; SANDBECK, K.A. Rapid methane oxidation in a landfill cover soil. Applied and Environmental Microbiology, v. 56, n. 11 , p. 3405-3411, nov. 1990
ZEHNDER, A.J.B.; BROCK, T.D. Anaerobic methane oxidation: occurrence and ecology. Applied and Environmental Microbiology, v. 39 n. 1, p. 194-204, jan. 1980.

ZEISS, C.A. Accelerated methane oxidation cover system to reduce greenhouse gas emissions from MSW landfills in cold, semi-arid regions. Water, Air, and Soil Pollution, v. 176, p. 285-306, jul. 1996.

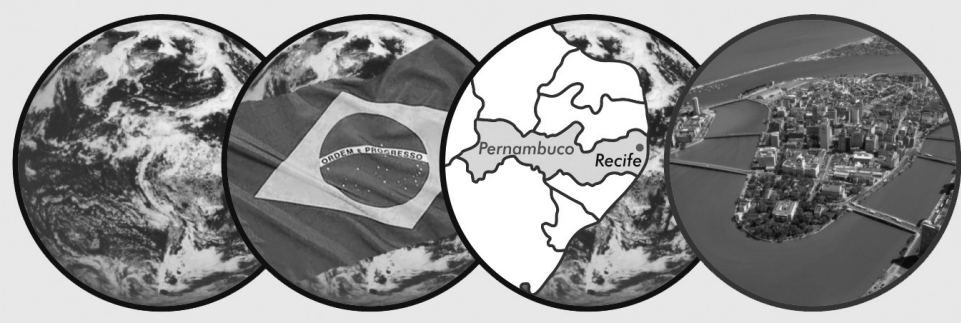

\section{$25^{\circ}$ Congresso Brasileiro de Engenharia Sanitária e Ambiental}

20 a 25 de setembro de 2009

Centro de Convenções de Pernambuco

Recife/PE - Brasil 